\title{
Challenges and Competencies of Leadership in Covid-19 Pandemic
}

\author{
Stefan Talu ${ }^{1, *}$ Nazarov A.D. ${ }^{2}$ \\ ${ }^{I}$ Technical University of Cluj-Napoca, The Directorate of Research, Development and Innovation Management \\ (DMCDI), Cluj-Napoca, 400020, Cluj county, Romania \\ ${ }^{2}$ Ural State University of Economics, Russian Federation \\ *Corresponding author.E-mail: stefan_ta@yahoo.com
}

\begin{abstract}
The objective of this article is to evaluate the impact of the COVID-19 pandemic on the challenges and opportunities for leadership. In conclusion, organizations need to apply measures to demonstrate a positive attitude of protection and care towards their employees, to adapt to new work schedules, and to build effective team relationships despite challenges. During this critical period, the leader should select the style of leadership that best suits the characteristics of this health situation, the subordinate, and the requirements of the job, so that, when necessary, he can take concrete measures to harmonize them with the tasks. At the same time, the leader must train and inspire, by his example, all subordinates by setting challenging goals, seeking improvement, emphasizing excellence in performance, and showing confidence that subordinates will work to high-quality standards. Also, we note that men leaders have superior competencies to females as leaders, especially in information technology skills. Leadership can be created by leaders with high skills (cognitive, functional, and social competencies) who can overcome challenges and take advantage of new opportunities to build competitive advantage strategies within the organization and to adopt change.
\end{abstract}

Keywords: COVID-19 pandemic, innovative approach, leadership competencies, vision.

\section{INTRODUCTION}

On 31 December 2019, the World Health Organization (WHO) China Country Office was informed of cases of pneumonia unknown etiology detected in Wuhan City, Hubei Province of China. The Chinese authorities identified a new type of coronavirus (COVID-19 / SARSCoV-2), which was isolated on 7 January 2020.

The global, deep, and accelerated COVID-19 crisis manifested itself at national, regional, and local levels (political, social, economic, financial, medical, educational, and human) on various coordinates with severe negative impact during all this period [1-4].

Economic uncertainty, fear for one's own life and that of those close to one, mass-media panic messages, complexity and ambiguity demonstrated by the political, economic, and medical environment have generated uncertainty in the correct assessment of the COVID-19 crisis, but also in setting priorities that could help mitigate the scale and consequences of such a pandemic.

At national, organizational, and individual levels, concrete reactive and preventive measures have been taken for effective COVID-19 pandemic management [5-8].

Government policies have intervened unevenly and uncertainly way to limit the impact of the pandemic on employment, to protect existing jobs, and to create effective conditions for job regeneration, which have already lost the social protection of the unemployed.

Community action and social distancing have been a central point of the community to reduce the impact of the epidemic and delay its peak, enabling healthcare systems to prepare for and cope with an increased influx of patients.

Countries have approached a policy of isolation by closing borders and acted quickly by restricting economic activity, by isolating the population at home, and by avoiding physical interactions between people.

The implementation and operation of an information system at the level of the entire enterprise and the digitization of work from home constituted flexible measures and working models that have adapted to an immediate response to the challenges of the COVID-19 crisis. However, these changes have generated stress, anxiety, panic, discomfort with high arousal, often negative emotions, abrupt shocks with gradual implications, reducing trust and attachment between organizations and their employees.

Numerous studies have been recorded in the literature over the years, in which researchers have perfected a general set of leadership practices that exemplary leaders apply in normal times, emphasizing that five common practices bring a decisive advantage in leading the organization and by that they accomplish special things in organizations (model the way; inspire a shared vision, challenge the process; enable others to act; encourage the heart) $[9,10]$. 
On the one hand, organizational leaders constantly apply their skills and knowledge, provided by human resources professionals, to create a calm, protective atmosphere for both the organization and their employees. At the same time in an actual crisis, the media network presents cases in which many leaders are blocked by these events and fail despite all their efforts to save organizations and jobs [10]. Within their communities, organizations as a whole in the current crisis are set in crisis mode and strive to meet the basic requirements of their customers, while maintaining the well-being and protection of their employees in a hostile environment.

In different studies, researchers have explored a variety of crises and the environments in which they occur, as well as the inherent risks present in organizational and leadership practices from multiple perspectives, focusing on manmade threats [11-13], but few data on leadership challenges and organizational outcomes arising from certain types of threats, such as COVID-19 are published [14-16].

During this period of uncertainty, employee morale is low, jobs are partially threatened by unemployment, and employees go through difficult times not being prepared to adapt to the new situation. Frequent and explicit communication between the leader and employees, as an integral part of crisis management, has a positive impact on the performance of the organization, creating relative safety at work and the personal situations of their employees.

The leader must have foresight, discipline, and objectivity, positive responsibility, clear environmental and situational awareness, and fight effectively with solid arguments against misinformation. The leader must first recognize the qualities of his subordinates, respect them, and validate them, which leads to increased loyalty and commitment to the organization. At the same time, through decisive adaptability, the leader must be flexible, prioritize needs and not react impulsively, and transmit information quickly on all levels.

The leader's decisions must be weighed and optimized to support the mental, emotional, and physical safety of employees, and from an organizational point of view, organizations will initiate collaboration instead of competition. Employees are most at risk of going through complex hard experiences and need two-dimensional support (emotional and interpersonal) to adapt to the new reality of work through respect, positive reinforcement, and appreciation of work.

It is known that leadership is a process by which a person influences others through character and competence to accomplish an objective and directs the organization in a way that makes it more cohesive and coherent. While leadership is learned, a leader's skills and knowledge are directly related to his or her attributes or traits, such as character, values, beliefs, and ethics. Knowledge and skills directly contribute to the creation of a harmonious and pragmatic vision intertwined with the art of communication in the leadership process, while the other attributes give the leader several multiple qualities and characteristics that give it uniqueness.
Leading an organization in a severe medical crisis is a stressful action, as the role and influence of the leader acquire a decisive role in times of change.

Strategic leadership is a key point for organizations, which can predict the essential changes and changes in advance and creates the right commitment and a suitable atmosphere for constructive or adaptive changes through processes (such as setting direction through vision, alignment, motivation, and inspiration) for the worker and teams to understand and adopt these changes successfully. A leader's innovative approach is characterized by a leader's ability to think, decide and act in a new or unique way, to promote and cultivate an innovative culture within organizations, motivating subordinates to bring new ideas, and achieve an adequate infrastructure to turn these ideas into reality.

Among the valuable human traits that the leader must possess are: the special talent to bring people together, to make them act together to achieve a common goal, to feel fulfilled by achieving outstanding performance. To earn respect, the leader must be ethical, convey a sense of direction that is achieved through a strong vision of the future, be realistic, tough, but fair, and show courage. People want to be guided by those they respect and who have a clear sense of direction. A leader must have integrity - the quality that makes people trust him. Trust is of vital importance in all interpersonal relationships. Integrity gives the impression of respecting standards or values outside of it, especially the truth. Trust, truth, and calm are primary values. He must show enthusiasm, warmth to attract people around him.

Leaders who demonstrate persistence, tenacity, determination, and synergistic communication skills will bring out the same qualities in their groups.

Leaders must be authentic, be able to build relationships, and mutual trust by engaging in active listening without prior judgment, communicating their opinions transparently, accepting advice and criticism, promoting calm and psychological security.

The leader in an organization must have to excel both internally and as members of the business community, complementing their skills with those of an innovative team, and having visible and authentic support on the objectives focused on the activity of the organization. Using flexible, multi-tiered work with clearly defined responsibilities, he must share his knowledge in courageous conversations with others to support work performance in the organization.

In this manuscript, we analyze the impact of the COVID19 pandemic on the competencies of leadership in the internal context, which we consider to be essential competencies for driving practices in response to a global health crisis.

\section{RESEARCH METHODOLOGY}

In this study, a set of questions was proposed: 1. Analysis of the managerial style during the COVID-19 pandemic? 
2. What are the leadership competencies required during the COVID-19 pandemic?

3. What is the importance of vision and innovative approach for leadership?

During July $1^{\text {st }}$ - August $31^{\text {th }}$, 2020, the Multifactorial Leadership Questionnaire (MLQ) 6S, prepared by B.M. Bass and B.J. Avolio [17] was applied to 40 leaders of small and medium-sized enterprises (SME) in ClujNapoca, Romania (20 men and 20 women), being completed by the subjects through the online platform. All participation in the studies was voluntary; all the participants received information on study aims and confidentiality. The leaders were Romanian men and females, with higher education, and served a minimum of 3 years within the field and at least one year in their leadership current position. The age of all participants varied between 44-56 years (average 49.6 years for men and 51.1 years for women), which showed a trend towards older people, characteristic of senior leadership levels in organizations.

Table 1 Characteristics of the total sample $(\mathrm{N}=40)$

\begin{tabular}{|c|c|c|c|c|}
\hline \multicolumn{3}{|c|}{ Variable } & Frequency [-] & Percent [\%] \\
\hline \multirow[t]{2}{*}{ Gender } & \multicolumn{2}{|r|}{ Male } & 20 & 50 \\
\hline & \multicolumn{2}{|r|}{ Female } & 20 & 50 \\
\hline \multirow{4}{*}{ Age } & \multirow[b]{2}{*}{ Male } & 44 to 50 years & 8 & 40 \\
\hline & & 50 to 56 years & 12 & 60 \\
\hline & \multirow[b]{2}{*}{ Female } & 44 to 50 years & 9 & 45 \\
\hline & & 50 to 56 years & 11 & 55 \\
\hline \multirow{8}{*}{$\begin{array}{l}\text { Years of experience in } \\
\text { leadership positions }\end{array}$} & \multirow{4}{*}{ Male } & Below 1 year & 2 & 10 \\
\hline & & 1 to 5 years & 7 & 35 \\
\hline & & 6 to 10 years & 8 & 40 \\
\hline & & Over 10 years & 3 & 15 \\
\hline & \multirow{4}{*}{ Female } & Below 1 year & 1 & 5 \\
\hline & & 1 to 5 years & 6 & 30 \\
\hline & & 6 to 10 years & 11 & 55 \\
\hline & & Over 10 years & 2 & 10 \\
\hline
\end{tabular}

Multifactor Leadership Questionnaire is considered the most frequently used and most valid tool for assessing leadership style, being applied in a wide range of organizations to leaders from different cultures. MLQ 6S is used for the systematic measurement of transformational leadership [18]. MLQ 6S contains 21 items, to which were added, for the present study, items related to demographic variables (age, gender) and seniority of subjects in leadership positions. Responses to MLQ items were recorded on a Likert scale $(0=$ not at all; $1=$ once in a while; 2 = sometimes; 3 = fairly often; $4=$ frequently, if not always). The items are designed to highlight 7 factors of leadership style, respectively: idealized influence (factor 1 ; items 1, 8, and 15 - score 9), inspirational motivation (factor 2; items 2, 9, and 16 - score 9), intellectual stimulation (factor 3; items 3, 10, and 17- score 9), individualized consideration (factor 4; items 4, 11, and 18
- score 9); contingent reward (factor 5; items 5, 12, and 19 - score 11); management-by-exception (factor 6; items 6, 13, and 20 - score 10) and laissez-faire leadership (factor 7 ; items 7, 14, and $21-$ score 4). Score range: high $=9-12$, moderate $=5-8$, low $=0-4$.

Transformational leadership includes four basic components: idealized influence, inspirational motivation, intellectual stimulation, and individualized consideration. Transactional leadership includes two basic components: contingent reward and management-by-exception. Laissezfaire leadership is non-leadership, where a leader abdicates responsibilities and avoids making decisions [19-23].

The results obtained from the application of the questionnaire were processed using SPSS 20 Statistical Package for the Social Sciences 20, using descriptive analysis, as well as parametric and non-parametric statistical tests.

Table 2 Total scores of the MLQ 6S factors

\begin{tabular}{|l|l|l|l|l|l|l|}
\hline Gender & Leadership style & Basic component leadership style & Mean & Median & Mode & Standard deviation \\
\hline & Transformational & Idealized influence & 9.83 & 10 & 10 & 0.98 \\
\hline
\end{tabular}




\begin{tabular}{|c|c|c|c|c|c|c|}
\hline \multirow{6}{*}{ Male } & & Inspirational motivation & 9.73 & 10 & 10 & 0.74 \\
\hline & & Intellectual stimulation & 9.81 & 10 & 10 & 0.83 \\
\hline & & Individualized consideration & 10.12 & 10 & 10 & 1.02 \\
\hline & \multirow[t]{2}{*}{ Transactional } & Contingent reward & 9.53 & 10 & 10 & 0.69 \\
\hline & & Management-by-exception & 10.11 & 10 & 10 & 0.94 \\
\hline & Laissez-faire & Laissez-faire & 1.34 & 1 & 1 & 0.16 \\
\hline \multirow{7}{*}{ Female } & \multirow[t]{4}{*}{ Transformational } & Idealized influence & 9.74 & 10 & 10 & 0.92 \\
\hline & & Inspirational motivation & 9.65 & 10 & 10 & 0.81 \\
\hline & & Intellectual stimulation & 9.87 & 10 & 10 & 0.78 \\
\hline & & Individualized consideration & 10.07 & 10 & 10 & 1.14 \\
\hline & \multirow[t]{2}{*}{ Transactional } & Contingent reward & 9.59 & 10 & 10 & 0.63 \\
\hline & & Management-by-exception & 10.25 & 10 & 10 & 0.89 \\
\hline & Laissez-faire & Laissez-faire & 1.12 & 1 & 1 & 0.11 \\
\hline
\end{tabular}

The validation of the research was ensured by analyzing the quality of the operationalization made, by verifying the correct application of the questionnaires, and by analyzing the credibility of the obtained results. All the four scales had high reliability, with the Cronbach alpha being not less than 0.91 . Results were considered significant when $\mathrm{p}<$ 0.05 , which reflects an association that has unlikely occurred due to chance or error.

Table 3 Average score for leadership style

\begin{tabular}{|l|l|l|l|l|}
\hline \multicolumn{1}{|c|}{ Age } & Gender & Leadership style & Mean & Standard deviation \\
\hline \multirow{3}{*}{44 to 50 years } & \multirow{3}{*}{ Male } & Transformational & 9.88 & 0.94 \\
\cline { 3 - 5 } & & Transactional & 9.78 & 0.76 \\
\cline { 3 - 5 } & Laissez-faire & 1.23 & 0.14 \\
\hline \multirow{3}{*}{44 to 50 years } & \multirow{3}{*}{ Female } & Transformational & 9.82 & 0.91 \\
\cline { 3 - 5 } & & Transactional & 9.81 & 0.72 \\
\cline { 3 - 5 } & Laissez-faire & 1.10 & 0.10 \\
\hline \multirow{3}{*}{50 to 56 years } & \multirow{3}{*}{ Male } & Transformational & 9.84 & 0.98 \\
\cline { 3 - 5 } & & Transactional & 9.75 & 0.69 \\
\cline { 3 - 5 } & Laissez-faire & 1.46 & 0.18 \\
\hline \multirow{3}{*}{50 to 56 years } & \multirow{3}{*}{ Female } & Transformational & 9.81 & 0.92 \\
\cline { 3 - 5 } & & Transactional & 9.79 & 0.63 \\
\cline { 3 - 5 } & Laissez-faire & 1.14 & 0.11 \\
\hline
\end{tabular}

communicating the standards to be met (item 20, p = 0.01) are priorities for female leaders.

\section{DISCUSSION}

The analysis of the answers obtained for the MLQ 6S items highlights the fact that, at the level of the entire sample, $90 \%$ of the subjects tended to focus their answers to the variants "fairly often" and "frequent, if not always", both for the items corresponding to transformational leadership, as well as those for transactional leadership.

Thus, based on the Mann-Whitney U test, we can conclude that female leaders communicate significantly more often their opinion about how team members do, compared to male leaders $(p=0.01)$. Female leaders motivated subordinates by presenting tasks in simpler terms than male ones; they also emphasized the importance of finding meaning in the tasks performed, to a greater extent than male leaders. Supporting subordinates for selfdevelopment efforts is a more common practice for women leaders in the sample involved in the study (item 4 , $\mathrm{p}=0.01$ ), and assisting others in finding meaning in work is a specific approach (item $16, \mathrm{p}=0.01$ ). Also, the explanation of the criteria that must be met to obtain the reward (item $5, \mathrm{p}=0.01$ ), the offering of recognition and reward (item 12, p = 0.01), the preference for
In the analysis of the results according to the age variable, statistically significant differences were confirmed for only one item (6. I am satisfied when others meet agreedupon standards). In this sense, the Kruskal-Wallis test was applied, which confirmed that there are statistically significant differences between the two age categories in

the attitude of leaders towards the way of performing tasks. It has been found that leaders under the age of 50 rarely want employees to meet agreed standards.

The results confirm the theory of full-range leadership on the adoption by leaders of skills and attitudes in both leadership styles (transformational and transactional) which complement each other and do not exclude each other.

The averages of the scores calculated for the three leadership styles show relatively close values for transformational and transactional leadership and very low values for passive leadership (Laissez-faire) (Table 3). Besides, the average values for transformational and laissez-faire leadership styles are higher for men than for women. For the transactional leadership style, the scores 
calculated for female leaders were significantly higher than those calculated by male leaders.

Also, the results confirm that younger leaders prefer transformational and transactional leadership style, and avoid laissez-faire leadership style. It is very rare to be involved in laissez-faire management in a time that varies from leader to leader or is not typical among all leaders (this fact being positive vis-à-vis their ability to manage change successfully).

The strengths of leadership were that leaders emphasized people-orientation, sensitivity to external stressors, the ability to manage multilaterally, and commitment to twoway communication through transformative leadership and the foundation of a vision. Sometimes during the crisis, the leaders had weaknesses, characterized by poor communication, impatience, inability to reverse decisions, mentioning nasty conflicts, the ability to be direct to a perfectionist attitude. At the same time, there were elements from the past that most influenced their leadership approach. They sometimes made unpopular decisions, which were balanced by promotions, offering rewards. The permanent use of motivational and interpersonal behaviors and influences was highlighted, which were seconded by solid cognitive and affective knowledge, which characterizes a good transformational leader in a crisis.

It is observed that most of the transformational leaders are from environments in which it was acceptable to fail if an attempt was made by various means to obtain a solution. But, in most cases, the leaders were sincere, to achieve their organizational objectives and efficiently manage all the resources at their disposal.

Leaders are entirely Christians and have adopted a concessive and understanding manner in solving the personal problems of employees.

The qualities and attributes of a leader in the face of a crisis require its approach with responsibility, calm, and optimism. However, the leader must manage emotional intelligence and emotional stability to place the interests of others above their own in leading the organization. This involves leadership in the faith, through total involvement, to overcome any prejudice of persistent normalcy and to collaborate effectively with subordinates. priority. In a time of high levels of stress at all levels (personal, professional, and social) leaders can intuitively impose the adaptive work needed to control their stress and that of others, to receive the full support of these stakeholders during the crisis, and more. On the other hand, the empathy of the leader is the priority in a crisis to provide both personal and professional support at the human level while maintaining organizational morale in crisis.

Internal management training is recommended, with specialized programs with internal experts or external management consultants to improve the skills adapted to this crisis, through an emphasis on self-confidence, to gaining people's respect.

\section{CONCLUSION}

This study presents three leadership practices for managing the unpredictable adaptation challenges of the COVID-19 pandemic in Romania.

A leader should place the interests of others above their own, possess intelligence and emotional stability, and focus on involvement and collaboration, to distribute leadership responsibilities to teams across the organization to optimize decisions made in solving complex problems. crisis.

Leaders need to use a variety of communication channels to convey information clearly and frequently to all stakeholders in a clear, comprehensive, and flexible style, with the ability to adapt to learn and evolve in crisis.

Leaders must have a clear goal-oriented vision, be riskaverse, and present innovative long-term strategic thinking to gain a competitive advantage. Leaders with creative force, brave to improve long-term behavior patterns, to apply organizational opinions and norms can successfully go through the transition to the health crisis with professionalism, understanding, and compassion. Adaptive leaders can take advantage of current strategic opportunities and impose new organizational responsibilities through innovation through new digital technology channels to continuously adapt to current changes.

A leader in organizational contexts in the COVID-9 pandemic must be coherent, flexible, account for his emotions, be involved, and listen to all the opinions of employees in order to carefully manage this period of crisis. Also, the leader is directly responsible for the financial aspects of the organization and must dose his efforts in risk situations. The ongoing COVID-19 pandemic will have a multilateral impact on organizations, and strategically oriented leaders will formulate goals to turn challenges into victories for themselves and their organizations.

\section{CREDIT AUTHORSHIP CONTRIBUTION STATEMENT}

Ştefan Ţălu: Conceptualization, methodology, investigation, writing, and editing. Anton Dmitrievich Nazarov: Supervision and validation. The authors have read and agreed to the published version of the manuscript.

\section{DECLARATION OF INTEREST}

The authors declare that they have no known competing financial interests or personal relationships that could have appeared to influence the work reported in this paper. No funds were used for this study. 


\section{REFERENCES}

[1] S.L. Șorcaru, Ș.C. Topliceanu, A.M. Ambrozie, The economic strategies of the great powers to response to the Covid-19 pandemic, EIRP Proceedings, 15(1), 2020 .

[2] B. Anthony Jnr, S.A. Petersen, Examining the digitalisation of virtual enterprises amidst the COVID19 pandemic: a systematic and meta-analysis, Enterprise Information Systems, 2020. DOI: 10.1080/17517575.2020.1829075.

[3] B.B. Forster, M.N. Patlas, F.J. Lexa, Crisis Leadership during and following COVID-19, Canadian Association of Radiologists' Journal 0846537120926 75, 2020. DOI: 10.1177/0846537120926752.

[4] S. Bartsch, E. Weber, M. Büttgen, A. Huber, Leadership matters in crisis-induced digital transformation: how to lead service employees effectively during the COVID-19 pandemic, Journal of Service Management, 2020. DOI 10.1108/JOSM-052020-0160

[5] J.J.V. Bavel, K. Baicker, P.S. Boggio, et al. Using social and behavioural science to support COVID-19 pandemic response. Nat Hum Behav 4, 460-471, 2020. DOI: $10.1038 / \mathrm{s} 41562-020-0884-z$.

[6] A.A. Fernandez, G.P. Shaw, Academic Leadership in a Time of Crisis: The Coronavirus and COVID - 19, Journal Of Leadership Studies, 14(1): 39-45, 2020. DOI: $10.1002 / \mathrm{jls} .21684$.

[7] Ş. Ţălu, Implications of modern digital technologies in higher education. Advances in Economics, Business and Management Research (AEBMR), 105: 554-557 (2019). DOI: 10.2991/iscde-19.2019.107.

[8] Ş. Ţălu, New perspectives in the implementation of smart-technologies in higher education. Advances in Economics, Business and Management Research (AEBMR), 138: $253-257 \quad$ (2020). DOI: 10.2991/aebmr.k.200502.042.

[9] J.M. Kouzes, B.Z. Posner, The Leadership Challenge: How to Make Extraordinary Things Happen in Organizations. San Francisco, CA: Jossey-Bass, 2012.

[10] K.M. Dirani, M. Abadi, A. Alizadeh, B. Barhate, R.C. Garza, N. Gunasekara, G. Ibrahim, Z. Majzun, Leadership competencies and the essential role of human resource development in times of crisis: a response to Covid-19 pandemic, Human Resource Development International, 23:4, 380-394, 2020. DOI: 10.1080/13678868.2020.1780078.

[11] R.A. Boin, From Crisis to Disaster: Toward an Integrative Perspective." In What is a Disaster? New Answers to Old Questions, edited by R. Perry and E.L. Quarantelli, 155-172. Philadelphia: Xlibris Press, 2005.

[12] C. Kayes, N. Allen, N. Self, How Leaders Learn from Experience in Extreme Situations: The Case of the US Military in Takur Ghar, Afghanistan. In Holenweger, edited by M. Holenweger, M. Jager, F. Kernic, 277-294. New York, US: Springer, Cham, 2017.

[13] C.L. Adkins, J.D. Werbel, J.L. Farh, A Field Study of Job Insecurity During a Financial Erisis. Group \& Organization Management 26: 463-483, 2001.

[14] J. McGuinness, 4 COVID-19 Leadership Lessons. Chief Executive, 2020. https://chiefexecutive.net/4covid-19-leadership-lessons/

[15] T. Brower, 5 Predictions about How Coronavirus Will Change the Future of Work." Forbes, 2020. https://www.forbes.com/sites/tracybrower/2020/04/06/h ow-the-post-covid-future-will-be-different-5-positivepredictions-about-the-future-of-work-to-help-yourmood-and-yoursanity/\#92e6193e227f

[16] K. Bogusky-Halper, Study: Organizations Rising to the Challenge of COVID-19 Communication, but Needs Persist; Leaders Must Address Concerns and Demonstrate Transparency, Clarity and Openness, Business Wire, 2020. https://www.businesswire.com/ news/home/20200403005278/en/STUDY-Organizations-Rising-Challenge-COVID-19-CommunicationsPersist

[17] B.M. Bass, B.J. Avolio, The Multifactor Leadership Questionnaire: Form 5x. Center for Leadership Studies, State University of New York, Binhampton, NY, 1991. https://www.mindgarden.com/ 16-multifactor-leadership-questionnaire

[18] P.G. Northouse, Leadership: Theory and practice. Thousand Oaks, California: Sage Publications, 2018.

[19] B.M. Bass, Transformational leadership: Industrial, military, and educational impact. Mahwali, NJ: Lawrence Erlbaum Associates, 1998.

[20] G. Vinger, F. Cilliers, effective transformational leadership behaviours for managing change, SA Journal of Human Resource Management, 4(2): 1-9, 2006. 
[21] S.E. Moon, P.J. Van Dam, A. Kitsos, Measuring Transformational Leadership in Establishing Nursing Care Excellence, Healthcare, 7(132): 1-11, 2019. DOI: 10.3390/healthcare7040132.

[22] A. Costache, Transformational leadership in romania's education system: preliminary results (September 03, 2018). Romanian Journal of Psychological Studies (RJPS), 2018, Available at SSRN: https://ssrn.com/abstract=3562165

[23] A. Guţu, The characteristics of a good leader, Scientific Annals Of The State University „B. P. Hasdeu "From Cahul, VII : 182-187, 2011. 